in 4 children. Only one echocardiogram was abnormal in a child in whom cardiomegaly was due to a small pericardial effusion that resolved spontaneously in a few weeks time. It is likely that this effusion was secondary to an underlying viral illness.

Conclusion Incidental finding of an abnormal cardiac silhouette on a CXR in children with no underlying cardiac symptoms or signs is not associated with an underlying structural or functional heart disease.

\section{G253(P) THE RISK OF DEVELOPING NECROTISING ENTEROCOLITIS IN INFANTS WITH CONGENITAL HEART DISEASE UNDERGOING INVASIVE CARDIAC PROCEDURES}

'LP Nellihela, ${ }^{1} \mathrm{H}$ Wang, ${ }^{2} \mathrm{M}$ Mutalib, ${ }^{1} \mathrm{~A}$ Hort, ${ }^{1} \mathrm{M}$ Upadhyaya. ${ }^{1}$ Department of Paediatric Surgery, Evelina London Children's Hospital, Guy's and St Thomas' NHS Foundation Trust, London, UK; 'Department of Paediatric Gastroenterology, Evelina London Children's Hospital, Guy's and St Thomas' NHS Foundation Trust, London, UK

\subsection{6/archdischild-2018-rcpch.246}

Aim Prematurity is the most significant risk factor for developing necrotising enterocolitis (NEC). However, congenital heart disease (CHD) is also a well-recognised risk factor. Our aim was to identify the incidence of NEC in term children undergoing invasive cardiac procedures.

Methods This was 5 year (January 2010 to December 2015) retrospective review of all infants admitted with CHD. Data was collected on demographics, NEC (incidence, clinical management and mortality) and invasive cardiac procedure (ICaP) defined as either open-heart surgery or cardiac catheterisation. Incidence of NEC was compared in the two groups (ICaP and non-ICaP). Institutional ethical approval was given. $\mathrm{p}$ value $<0.05$ was significant.

Result 5103 infants with CHD were identified. $31.5 \%$ $(n=1608)$ patients had an ICaP.Overall 128/5103 (2.5\%) of patients developed NEC: 102/1608 in ICaP group; 26/3495 in non ICaP group, $\mathrm{p}<0.001$. Median gestational age was 37 weeks (range 29 to 42). Median age at presentation was 6 weeks (range 0.4 to 104). The most common cardiac diagnoses were, hypoplastic left heart 45 (33.5\%), ventricular septal defect (VSD) 16 (12\%), isolated PDA 10 (7.4\%).60 had multiple cardiac procedures and 42 had a single cardiac procedure, $\mathrm{p}>0.5$.

$52 \%(n=66)$ of patients had pneumatosis and $7 \%(n=9)$ had pneumoperitoneum. 79\% $(\mathrm{n}=101)$ of patients were managed conservatively. 21\% (27/128) required surgery: 18/27 (67\%) in ICaP and $9 / 27$ in non-ICaP group, $p>0.5$. Multiple cardiac procedures significantly increased the risk of needing a laparotomy, $\mathrm{p}=0.01$. Intraoperatively, $44 \%(n=12)$ had a bowel perforation and rest had significant NEC. $41 \% \quad(n=11)$ had primary resection and anastomosis; $16 / 27$ had a stoma.Overall mortality was 7\%: 5 patients died pre-operatively and 4 patients died post-operatively, however an ICaP was not a significant factor for mortality in NEC ( $p>0.5)$.

Conclusion Invasive cardiac procedure is a significant factor in developing NEC in term infants. A single ICaP did not increase the risk for either needing laparotomy or mortality, but multiple cardiac procedures did further increased the risk for laparotomy in children with NEC. This information could be used for counselling and risk stratifying cardiac patients.

\section{G254(P) CHANGING PATTERN OF NEONATAL PDA LIGATION ACROSS A NETWORK}

${ }^{1,2} \mathrm{M}$ Chalia, ${ }^{1,2}$ S Broster, ${ }^{3} \mathrm{R}$ Roy, ${ }^{4} \mathrm{~S}$ Somisetty, ${ }^{1,2} \mathrm{AW}$ Kelsall. ${ }^{1}$ Neonatal Intensive Care Unit, Rosie Hospital, Cambridge University Hospitals NHS Foundation Trust, Cambridge, UKi ${ }^{2}$ Acute Neonatal Transfer Service (ANTS), East of England, NHS, Cambridge University Hospitals NHS Foundation Trust, Cambridge, UK; ${ }^{3}$ Neonatal Intensive Care Unit, Norfolk and Norwich University Hospitals NHS Foundation Trust, Norwich, UK; ${ }^{4}$ Neonatal Intensive Care Unit, Luton and Dunstable University Hospital, Luton, UK

\subsection{6/archdischild-2018-rcpch.247}

Introduction The management of the neonatal patent ductus arteriosus (PDA) remains controversial and subject to much debate. There is uncertainty about the type and timing of medical therapies. There are concerns about the long-term outcome after surgical ligation. Previous studies from our network suggested improved survival. ${ }^{1}$ Subsequent work highlighted different referrals practices by the tertiary neonatal intensive care units (NICUs). The aim of this service evaluation was to review changing practice across this network over the last 18 years following a more standardised network approach of referral since 2013 .

Methods Patients were identified from the Acute Neonatal Transport Service(ANTS) database. All infants requiring PDA ligation were transported by them to cardiac centres for surgical ligation between January 2004 and July 2017.

Results Over this period 252 neonates have been referred for PDA ligation. The numbers referred annually were a median of 15 (range 5-36), with a peak of 36 referrals in 2011. Most referrals (77\%) were from the three tertiary NICUs. Prior to 2011 there was a clear difference in referral rates. Conclusions A more standardised approach, where usually only infants who had failed extubation were referred for PDA ligation has resulted in a substantial reduction in the number of infants undergoing surgical closure. This reduction is not the result of a changing neonatal population nor a change in specific medical therapies to treat the PDA in any of the units. It almost certainly reflects more tolerance of a PDA alongside careful ventilation, fluid, and nutrition management.

\section{REFERENCE}

1. Kang SL, et al. Cardiology in the Young 2013;(23):711-716.

\section{G255(P) AORTIC AND PULMONARY ARTERY CALCIFICATION IN TWIN-TO-TWIN TRANSFUSION SYNDROME}

${ }^{1} \mathrm{R}$ Udaya Prasad, ${ }^{1} \mathrm{SV}$ Rasiah, ${ }^{2} \mathrm{~T}$ Desai. ${ }^{1}$ Neonatal Intensive Care, Birmingham Women's and Children's Hospital NHS Foundation, Birmingham, UK; '2Pediatric Cardiology, Birmingham Women's and Children's Hospital NHS Foundation, Birmingham, UK

\subsection{6/archdischild-2018-rcpch.248}

Introduction Twin-to-twin transfusion syndrome (TTTS) is a rare disorder occurring as a result of communicating vascular anastomosis between the circulations of one twin with that of the other. Cardiac findings in this condition may include ventricular hypertrophy, pulmonary stenosis, tricuspid regurgitation, congestive cardiac failure, left ventricle hypoplasia with hypokinesia, and sub-aortic obstruction seen in the recipient twin. Isolated great artery calcification; aortic and pulmonary artery calcification is one such uncommon condition associated with TTTS. It may cause severe systemic hypertension and 